have been made which confirm the similarity. There is a danger in over-simplification; a culture name can easily become a sort of dustbin into which many different discoveries are thrown.

Dr. van Riet Lowe has also contributed a short article in Portuguese for the Sociedade de Estudos da Colonia de Moçambique (Boletim Nos. 57-58; April-September 1948). Anything that can be done in the way of creating interest in archæological matters in this part of Africa is to be welcomed. Dr. van Riet Lowe has also given a useful summary (British Science News, 2, No. 16) of the archæology of some of Dr. Robert Broom's famous sites in the Transvaal. Finally, in Volume 3, Bulletin No. 12 of the South African Archæological Society, Cape Town, Dr. B. D. Malan describes a new Middle Stone Age site near Utrecht, Natal.

M. C. BuRKITT

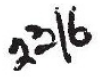

\section{RADAR RESEARCH AND DEVELOPMENT ESTABLISHMENT, MALVERN}

\footnotetext{
T
} HE Radar Research and Development Establishment of the Ministry of Supply held a series of open days athelvern during the period September 21-23, thus giving the public its first chance of seeing the fork of this well-known Establishment.

The fadar Research and Development Establishmeñ is nesponsible for the research and development aspec s of army radar equipment, both for the direction of anti-aircraft, coast and field artillery, and for the location of shipping, land vehicles and missiles. Although its history can be traced back to the Searchlight Experimental Establishment formed in 1917, the radar work which now absorbs the whole of the effort of the Establishment originated in a small research group detached to work at the Air Ministry Bawdsey Research Station in 1936 under the direction of Mr. (now Sir Robert) Watson-Watt. Whereas the Bawdsey Research Station was primarily concerned with radar for the Royal Air Force and later became the Telecommunications Research Establishment, the group concerned with developing radar to meet the army requirements broke away in 1939 to rejoin the parent Establishment and to form what might be termed the nucleus of the present Radar Research and Development Establishment at Christchurch in Hampshire. The Establishment moved to Malvern in 1942. Among a number of men of science who have directed its work since its inception, one finds Dr. J. D. (now Sir John) Cockcroft, who was chief superintendent during 1941-44. The present chief super. intendent is Mr. P. E. Pollard, who was a member of the original research team under Sir Robert WatsonWatt in 1936.

The exhibition was opened on September 21 by the Minister of Supply, Mr. G. R. Strauss, and attendance on this day was limited to leading representatives of the fighting Services, the Civil Service, universities and industry, together with the Press. On September 22 the exhibition was attended by more than a thousand members of other government establishments, the universities and industry, while on the last day members of the general public were admitted. The impressive list of exhibits numbered more than a hundred, and a selection of the more interesting items is described below.
Anti-aircraft Gun-laying Radar. The purpose of the gun-laying radar is to provide accurate and continuous information of the position of an aeroplane or other target so that a 'predictor', or other computing equipment, can calculate where the gun should be pointed in order that the shell shall be effective against the target. There were eleven exhibits covering the work of the Establishment on gun-laying radar, including examples of the various types of set built dating from the $6 \frac{1}{2}$-metre wave-length, range and bearing only, set of 1939 to the modern $10-\mathrm{cm}$. wave-length 'auto-follow' system. In this modern set a paraboloid of about $5 \mathrm{ft}$. aperture forms the aerial system. In place of the normal hand turning, the aerial is automatically driven by servo-motors controlled by the radar pulses reflected back from the target in such a way that it continues to point at the moving target. The result is that the position of the target is accurately indicated and followed, however it may 'jink' or turn, without the aid of a human operator. An impressive exhibit showed this 'automatic-follow' radar coupled up through a predictor to a battery of four heavy anti-aircraft guns which fired demonstration rounds at a passing high-speed aircraft. The whole operation, apart from the actual loading of the guns, appeared to be completely automatic.

Field-artillery and Coast-artillery Radar. Fieldartillery radars are required to detect enemy vehicles, to locate enemy mortar positions from observations of mortar trajectories, and to assess the accuracy of gunfire by observation of point of impact of shells. Similarly, coastal-artillery radars are required to detect enemy ships and to direct the fire of coastal batteries.

The $3-\mathrm{cm}$. wave-length coastal-artillery radar exhibited has a rather unusual display in that in addition to the normal sector-scanned plan-positionindicator display, facilities are provided for 'strobing' out a portion of the sector in both range and bearing, enabling an enlarged picture to be displayed on a second cathode ray tube. The result is that when the set is used for directing artillery fire against shipping, one is able to get a plan view of the ship on the magnified display. In addition, the resolution of the set is so good that the shell splashes are also clearly indicated, enabling small corrections to be applied to the direction of fire until a shell is actually seen to fall on the ship.

Radar for Ballistic Measurements. Ten exhibits were devoted to showing the application of radar to the determination of speed, spin and direction of experimental rockets and other projectiles. Velocity and spin measurements are normally made by observation of the Doppler frequencies produced by the recession of the target on a continuous wave (as opposed to the normal pulse) radar. An interesting exhibit in this group showed a tiny rocket-propelled missile which was followed on a $3-\mathrm{cm}$. wave-length continuous-wave radar during its flight. The Doppler frequency produced by beating the outgoing and returning radio signals could be heard on a loudspeaker and was fed to a frequency-measuring meter which indicated the speed of the missile in miles per hour.

Radar Aerial Research. Of the research items shown, some of the most interesting were due to the group working on aerials. In addition to simple demonstrations showing the focusing properties of the usual dipole arrangements, Yagi and paraboloid aerials, a considerable amount of new work on metal 
plate, rod, delay and variable refractive index lenses was shown. One exhibit showed a large metal-plate lens of $8 \mathrm{ft}$. aperture and focal length $11 \mathrm{ft} .8 \mathrm{in}$. operating on a wave-length of $10.7 \mathrm{~cm}$. The horn feed for this lens was traversed to and fro across the focal plane, and monitor receiver aerials indicated that the beam scanned over $\pm 18^{\circ}$ with a loss of less than 2 decibels at the extremities of the scan. A further exhibit in this section showed apparatus for the automatic recording of phase and amplitude distribution in the wave-front across the aperture plane of experimental lenses.

General Research Items. A number of research items, the results of which aim at producing radar sets giving better performance, was shown. These items covered a wide field and included work on the magnetic clutch principle initiated at the National Bureau of Standards in the United States. The clutch relies for its action on the fact that a 'sludge' of fairly low viscosity, produced by immersing iron filings in oil, solidifies when subjected to a magnetic field. This work aims at producing improved servo-motor drives. Another interesting exhibit demonstrated the production of a standard milliwatt of power on a wave-length of $10 \mathrm{~cm}$. for the calibration of radar receivers, while new techniques and developments in radar test gear and electro-chemistry were also shown.

Workshop Exhibits. Essential to the success of modern research workers is the co-operation of firstclass workshops. The dozen or so exhibits in the workshops of the Establishment indicated just how well its scientific workers are served in this respect. A fine collection of modern machine tools was shown with examples of turning, milling, grinding, moulding and plating. Examples of completed work included a large centrifuge capable of subjecting weights of $150 \mathrm{lb}$. to $200 \mathrm{~g}$.

A film entitled "Debellamus Superbos", describing the work of the Establishment from the earliest sound-locating equipment to the present-day radar, was shown each day during the exhibition.

F. E. JONES

1346

\section{ASSOCIATION OF SPECIAL LIBRARIES AND INFORMATION BUREAUX}

\section{ANNUAL CONFERENCE}

$\mathrm{T}$ HE twenty-forth annual conference of the Association o Special Libraries and Information Bureaux, the fint to be held since the amalgamation of the Assod atiol with the British Society for Internationd Billiography, presented comparatively few features of interest to scientific workers generally. Although rather more than two hundred were present at Ashorne Hill, Leamington Spa, during the weekend September 9-12, and the attendance represented a wide range of interests, the Conference in some ways did not quite provide the opportunity for discussion of the Association's own affairs that was usually given by the annual general meeting, nor was the gap filled by Dr. Percy Dunsheath's reference to the early history of the Association at the outset of his presidential address on the Saturday morning.
The main features of Dr. Dunsheath's address wëre his references to the inadequacy of present-day facilities for reference libraries in science and technology and to the need for establishing higher standards of training and qualification for the stafis employed in scientific and technological libraries. Both these matters, he considered, call for strong action, and he maintained that the present reference library facilities in science and technology are a disgrace to Great Britain. An intensively indus. trialized country like Britain is particularly dependent on the ready dissemination of existing knowledge among scientific men and technologists; yet stocks of books are not readily available on account of lack of space, grants for new books are falling more and more into arrears and the flood of new knowledge is increasingly beyond the capacity of the under-paid, under-staffed and under-equipped librarian. Dr. Dunsheath said that the Patent Office Library is the most useful technical library in London and the best for its purpose in the United Kingdom, but he complained that it is now closed at 6 p.m. instead of at 10 p.m., while delays in binding, the absence of books from open shelves and the inadequacy of staffmainly due to a cut in the budget-seriously hinder its usefulness. Much the same criticism could be made of the Science Museum Library at South Kensington, and Dr. Dunsheath urged that provision of a new Library of Science and Technology in the centre of London, conceived on a grand scale, and using the practical experience and tradition of the Patent Office Library, would be the best contribution which the Government could make to our prosperity at the present time.

Following Dr. Dunsheath's address at a session on business archives, papers were given by Mr. F. G. Emmison, county archivist, Essex Record Office, and Mr. E. C. Baker, librarian and archivist of the Post Office, which were designed to assist members in selecting papers for retention, and which also discussed such archives as sources of history of business or industrial enterprises. Three papers presented at the afternoon session, which described the starting and operation of three new libraries, should be of particular interest to those who may be concerned with the formation and management of new research libraries or information centres. In one of those the library of the Institute of the Motor Industry was described by its librarian, Mr. C. E. C. Hewetson. Miss M. Gossett described the formation and operation of the library of the Atomic Energy Research Establishment at Harwell, and Mr. E. Ower, intelligence officer to the British Shipbuilding Research Association, the library of that Association.

The third session of the Conference, on Sunday morning, was concerned with the extraction of commercial and technical information from correspond. ence files, and the two papers presented by Mr. D. V. Arnold and Miss E. W. Parker considered both the most suitable techniques and the problem of ultimate storage. The fourth session, on Sunday afternoon, discussed the problems of obtaining official publications of interest, but centred essentially around those issued by H.M. Stationery Office, the director of which, Mr. W. Cox, contributed one of the three papers. The contents and arrangement of the daily, monthly and annual lists or catalogues issued by H.M. Stationery Office received some comment, while Miss Barbara Kyle dealt with problems presented by the United Nations Organisation's documents. 